\title{
Simulation of Machining of Incoloy 907 based on Thermodynamics
}

\author{
Fang Shao \\ School of Mechanical \\ Engineering,Binzhou \\ Polytechnic ,Binzhou,China 256603; \\ bzshaofang999@163.com
}

\author{
Lijing Zou \\ School of Mechanical Engineering, \\ Bin Zhou Polytechnic, \\ Binzhou,China 256603 \\ zlj08221105@126.com
}

\author{
Xuan Gao \\ Jiangsu Science and Technology \\ Information Institute, \\ Nanjing, China 210042 \\ ytxwz4001@163.com
}

\begin{abstract}
Aero-engine alloys (also as known as superalloys)are known as difficult-to-machine materials, especially at higher cutting speeds, due to their several inherent properties such as low thermal conductivity and their high reactivity with cutting tool materials. In this paper a finite element analysis (FEA) of machining for Incoloy907 is presented. In particular, the thermodynamical constitutitve equation(T-C-E) in FEA is applied for both workpiece material and tool material. Cutting temperature and cutting force are predicted. The comparison between the predicted and experimental cutting temperature and cutting force are presented and discussed. The results indicated that a good prediction accuracy of both principal cutting temperature and cutting force can be achieved by the method of FEA with thermodynamical constitutitve equation.
\end{abstract}

Keywords-Incoloy907,Simulation, constitutitve equation

Thermodynamical

\section{INTRODUCTION}

Superalloys are especially an important class of aerospace engineering materials due to their excellent combination of strength and fracture toughness as well as low density ${ }^{[1-5]}$. However, these materials are regarded as difficult to machine because of their low thermal conductivity and high chemical reactivity with cutting tool materials. Machinability is the term used to describe how easily a material can be cut to the desired shape (surface finish and tolerance) with respect to the tooling and machining processes involved. In a machining operation tool life achieved, metalremoval rate, component forces and power consumption, surface finish generated and surface integrity of the machined component as well as the shape of the chips can all be used to measure machinability. The machinability index can be significantly affected by the propertiesof the material being machined, properties and geometry of the cutting tool, cutting conditions employed and other miscellaneous factors such as rigidity of the machine tool, cutting environment, etc. Machining productivity can be significantly improved by employing the right combination of cutting tools, cutting conditions and machine tool that will promote high speed machining without compromising the integrity and tolerance of the machined components. This is particularly essential for the

This project is supported by the Natural Science Foundation of ShandongProvince(ZR2010EQ041) economic machining of difficult-to-cut aero-engine alloys whose peculiar characteristics generally impair machinability.

The wide spread use of jet engine has increased demand for materials that have excellent high temperature mechanical and chemical properties relative to steels and stainless steel alloys originally employed in jet engine applications. Demand for hotter, more powerful and more efficient engines led to the development of "super-stainless" alloys, or superalloys, Heat resistant alloys with high melting temperatures are major materials used in the manufacture of aero-engine components. These exotic superalloys can be grouped into four major categories: Nickel base alloys; cobalt base alloys; iron base alloys (e.g. high chromium stainless steel) and titanium alloys. Nickel base superalloys[6-8] are used as marine equipment, nuclear reactors, petrochemical plants, food processing equipment and pollution control apparatus. Titanium alloys[9-13] were developed in order to satisfy the need for a class of strong and light weight materials for aircraft engine and airframe manufacture, because of their outstanding strength to density ratios. The melting temperature of cobalt base alloys[14] are higher than nickel or iron base alloys, hence they are widely used in turbine vane applications as well as where corrosion resistance is of vital importance e.g. orthopaedic applications in the medical industry. The main use of iron base superalloys, that are weaker at elevated temperatures than nickel alloys, are in chemical processing applications such as heat exchanger, piping, retorts, mixing tanks, heat treatment equipment, muffles, conveyors, baskets and boxes [15-16]. In order to increase productivity and tool life in the machining of superalloys, it is necessary to develop a reliable FE model for conventional cutting speed regime, especially, for high speed machining. In recent years, the Johnson-Cook's constitutive equation is always used as a finite element model to simulate orthogonal cutting of Ti6Al4V alloy. Although such model is widely used in finite element simulations to describe the constitutive behavior of metals at high strain rates over a wide range 
of temperatures, its applicability over a wide range of strain is however limited due to the use of split Hopkinson's pressure bar method (SHPB) that permits to achieve only a limited range of strains.

However, little literature on researches of tool wear based on thermodynamics constitutive mechanism is reported until now. The aim of this study is to deduce the thermodynamical constitutive equation of Incoloy 907 at high temperature, which is used to build an orthogonal FE model during high speed machining of Incoloy 907.

\section{SimULATION}

The simulated cutting conditions are identical to those of the experiments performed on numerically controlled lathe utilizing a radial feed (Fig.1) at cutting speeds (v) of $300 \mathrm{~m} / \mathrm{min} 、 200 \mathrm{~m} / \mathrm{min} 、 150 \mathrm{~m} / \mathrm{min}$ and 100 $\mathrm{m} / \mathrm{min}$, uncut chip thickness (b) of $0.15 \mathrm{~mm}$ and width of cut(ap) of $0.5 \mathrm{~mm}$. The cutting temperature (along the rake face in Fig.2) was measured using a infrared thermal imager and the cutting force was measured using a dynamometer. The chemical composition of workpiece material is shown in Table 1 . The mechanical and physical properties of workpiece material and tool material are also presented in Table 2 and Table 3, respectively. The cutting tool geometry for WC CNMA432 consisted of a normal rake angle and a normal flank angle of $3^{\circ}$ and $7^{\circ}$, respectively. The tool cutting edge angle is $90^{\circ}$, the tool cutting edge inclination angle is $0^{\circ}$. No cutting fluid was used in the tests.

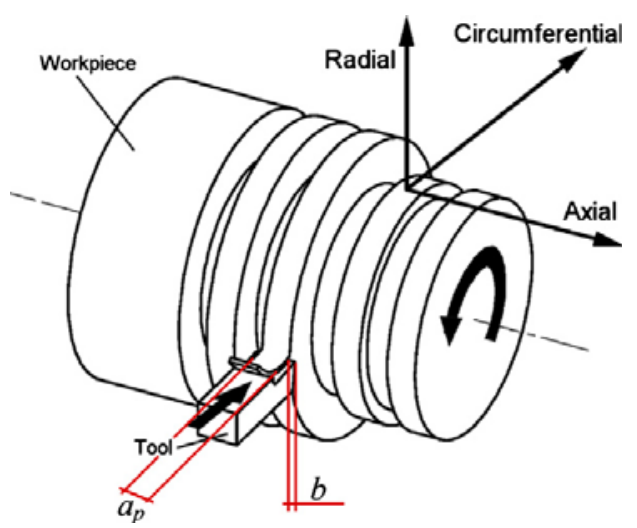

Figure 1. Configuration of the orthogonal cutting tests

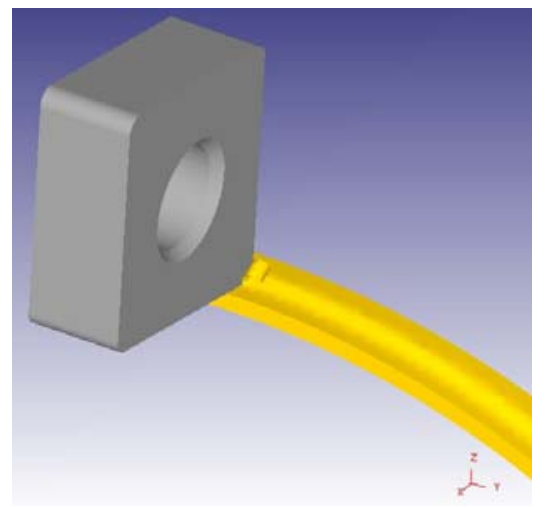

Figure 2. Tool and workpiece

TABLE 1. CHEMICAL COMPOSITION OF INCOLOY $907^{[17]}$

\begin{tabular}{|c|c|c|c|c|c|c|c|}
\hline element & $\mathrm{C}$ & $\mathrm{Ni}$ & $\mathrm{Co}$ & $\mathrm{Ti}$ & $\mathrm{Fe}$ & $\mathrm{Nb}+\mathrm{Ta}$ & $\mathrm{Si}$ \\
\hline $\begin{array}{c}\text { Component } \\
\text { (wt.\%) }\end{array}$ & $\leqslant 0.06$ & $35-40$ & $12-16$ & $1.3-1.8$ & 其余 & $4.3-5.2$ & $0.07-0.35$ \\
\hline
\end{tabular}

TABLE 2. MECHANICAL AND PHYSICAL PROPERTIES OF INCOLOY $907^{[17]}$

\begin{tabular}{|c|c|}
\hline Density & $8280 \mathrm{~kg} / \mathrm{m} 3$ \\
\hline Ultimate tensile strength & $1035 \mathrm{MPa}$ \\
\hline Tensile yield strength & $725 \mathrm{MPa}$ \\
\hline Modulus of elasticity & $160 \mathrm{GPa}$ \\
\hline thermal conductivity & $15.6 \mathrm{~W} /(\mathrm{m} . \mathrm{K})$ \\
\hline Poisson's ratio & 0.36 \\
\hline Heat capacity & $431 \mathrm{~J} / \mathrm{kg} \mathrm{K}$ \\
\hline
\end{tabular}

TABLE 3. MECHANICAL AND PHYSICAL PROPERTIES OF TOOL MATERIAL $\mathrm{WC}-\mathrm{CO}^{[18]}$

\begin{tabular}{|c|c|}
\hline Density & $14.5^{*} 103 \mathrm{~kg} / \mathrm{m} 3$ \\
\hline Ultimate tensile strength & $3000 \mathrm{MPa}$ \\
\hline Modulus of elasticity & $650 \mathrm{GPa}$ \\
\hline thermal conductivity & $58.9888 \mathrm{~W} /(\mathrm{m} . \mathrm{K})$ \\
\hline Poisson's ratio & 0.25 \\
\hline Heat capacity & $15.0018 \mathrm{~J} / \mathrm{kg} \mathrm{K}$ \\
\hline
\end{tabular}

\section{A. Numerical model of orthogonal machining}

The commercial FEA software DEFORM-3D, a Lagrangian implicit code, is used to simulate the orthogonal cutting process of Incoloy 907. FEM model of the orthogonal cutting process is developed that the tool is no longer modeled as rigid.(Fig2). The workpiece is initially meshed with 8000 isoparametric quadrilateral elements, while the tool is modeled as non-rigid, and meshed and subdivided into 1000 elements(Fig3). A plane-strain coupled the thermo-mechanical analysis is performed using orthogonal assumption.

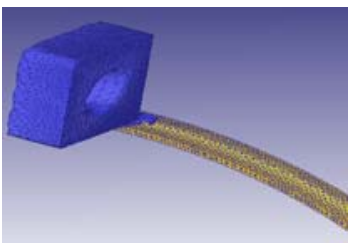

Figure 3. Meshed Tool and workpiece 


\section{B. Material modeling}

To model the thermo-elas plastic behaviour of workpiece material Incoloy 907 and tool material WC-Co, the thermodynamics constitutive equation which is expressed as equation $(1)^{[19]}$ is deduced and is used in this paper

$\sigma=\left(B \varepsilon_{p}^{n}\right)\left(1+B_{1} T\left[\dot{\varepsilon}_{P}\right]^{\frac{1}{m}}-B_{2} T e^{A\left(1-\frac{T}{T_{t}}\right)}\right)+Y_{a}$

Where A、B、B1、B2、 $\mathrm{n} 、 \mathrm{~m}$ and $\mathrm{Ya}$ are seven constants associated with material.

Medeling of material constitutive behavior in a variety of applications is important. The conventional tension or compression tests are only applicable under low strain-rates(10-3-10-1/s) and low temperature. In the machining processes, chip deformation, material constitutive relationships, and tool-chip friction are coupled together and affected each other.

According to principle of minimum energy dissipation, the occurrence of any process will happen on the least energy-consuming way, so as the plastic deformation of cutting process. The thermodynamics constitutive equation is deduced according to principle of minimum energy dissipation, which has taken into account coupling in the derivation, so the application of thermodynamics constitutive equation in simulation will be a new exploration in machining.

\section{1) Determination of parameters}

a) Doing orthogonal cutting experiments to collect cutting force date Fz、Fy, and to measure the thickness of chip.

b) calculating the ratio of the actual cutting force obtained from experiment and the ratio of the actual chip deformation coefficient obtained from experiment

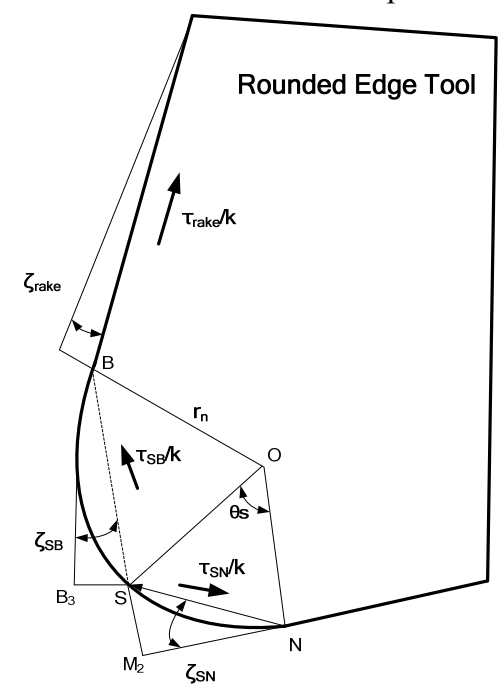

Figure4. Rounded edge tool c) calculating the ratio of the predicted cutting force and the ratio of the predicted chip deformation coefficient Cross-sectional of rounded edge tool is as follows(Fig.4)

trake/ $\mathrm{k}$ is the ratio of shear stress and flow stress of workpiece materials in the rake face, Crake is an angle associated with the above ratio, $\tau \mathrm{SB} / \mathrm{k}$ is the ratio of shear stress along the tool arc cutting edge SB and flow stress of workpiece materials in the rake face, $\zeta \mathrm{SB}$ is an angle associated with the above ratio; $\tau \mathrm{SN} / \mathrm{k}$ is the ratio of shear stress along the tool arc cutting edge $\mathrm{SN}$ and flow stress of workpiece materials in the rake face, $\zeta \mathrm{SN}$ is an angle associated with the above ratio; $\theta \mathrm{s}$ is central angle of residual layer of the formation of point $\mathrm{S}$ with the tool edge end point N.

i Assuming $\tau_{\text {rake }} / k=\tau_{S B} / k=\tau_{S N} / k=0.5$ and $\theta s=10^{\circ}$

ii Calculating the angle $\xi_{\mathrm{SB}}, \xi_{\mathrm{SN}}$ and $\xi_{\text {rake }}$

$$
\begin{gathered}
\zeta_{S B}=\left[\cos ^{-1}\left(\tau_{S B} / k\right)\right] / 2 \\
\zeta_{S N}=\left[\cos ^{-1}\left(\tau_{S N} / k\right)\right] / 2 \\
\zeta_{\text {rake }}=\left[\cos ^{-1}\left(\tau_{\text {rake }} / k\right)\right] / 2
\end{gathered}
$$

iii Calculating the theoretical thickness of chip

$$
h_{c h}=\sqrt{2} \cos \left(\pi / 4-\zeta_{\text {rake }}\right)\left(B H \cos \zeta_{\text {rake }}+S B \cos \zeta_{S B}\right)
$$

Where

$$
\begin{gathered}
B H=\frac{h c+\sqrt{2}\left(\Delta S+S B \cos \zeta_{S B}\right) \sin \delta-r_{n}\left(1+\sin \gamma_{0}\right)}{\left(\cos \zeta_{\text {rake }}+\sin \zeta_{\text {rake }}\right) \sin \left(\gamma_{0}+\zeta_{\text {rake }}\right)} \\
S B=2 r_{n} \sin \left(\frac{\pi}{4}+\frac{\gamma_{0}}{2}-\frac{\theta_{s}}{2}\right) \\
\Delta S=\sqrt{2} r_{n} \sqrt{1-\frac{\tau_{S N}}{k}} \sin \left(\frac{\theta_{s}}{2}\right) \\
\delta=\pi / 4-\gamma_{0}-\zeta_{\text {rake }}
\end{gathered}
$$

iv Calculating the sheer angle $\varphi, \varphi=\gamma_{0}+\xi_{\text {rake }}$

F. Calculating the ratio of the predicted cutting force and the ratio of the predicted chip deformation coefficient

$$
\left(\frac{F_{z}}{F_{y}}\right)_{p r}=\frac{1}{\tan \left(\operatorname{atan}\left(\frac{\tau_{\text {rake }}}{k}\right)-\gamma_{0}\right)}
$$




$$
\zeta_{p r}=\frac{h_{c h}}{h_{c}}
$$

If the predicted value and the actual value can meet with the following relationship, then export the flow stress strain strain rate and temperature ; if not, then re-assume the value of $\tau_{\text {rake }} / \mathrm{k}=\tau_{\mathrm{SB}} / \mathrm{k}=\tau_{\mathrm{SN}} / \mathrm{k}$ and $\theta \mathrm{s}$, till meeting the following relationship.

$$
\left[\left(\frac{F_{z}}{F_{y}}\right)_{p r}-\left(\frac{F_{z}}{F_{y}}\right)_{e x}\right]^{2}+\left[\left(\frac{h_{c h}}{h_{c}}\right)_{p r}-\left(\frac{h_{c h}}{h_{c}}\right)_{e x}\right]^{2} \leq 10^{-12}
$$

d) Calculating the flow stress strain ,strain rate and temperature with the following equations.

$$
\begin{gathered}
\sigma=k=\frac{F_{z}}{A}=\frac{F_{z}}{h_{c} w} \\
\gamma=\frac{\cos \gamma_{0}}{2 \sin \phi \cos \left(\phi-\gamma_{0}\right)} \\
\dot{\gamma}_{a v e}=\frac{v_{s}}{\Delta S} \\
T=T_{w}+\eta\left[\frac{\cos \gamma_{0}}{\cos \left(\phi-\gamma_{0}\right)} v_{c}\right. \\
\left.v_{s} S \frac{k \cos \gamma_{0}}{\sin \phi \cos \left(\phi-\gamma_{0}\right)}\right]
\end{gathered}
$$

The flow chat of calculating the four parameters is as follows(Fig.5).

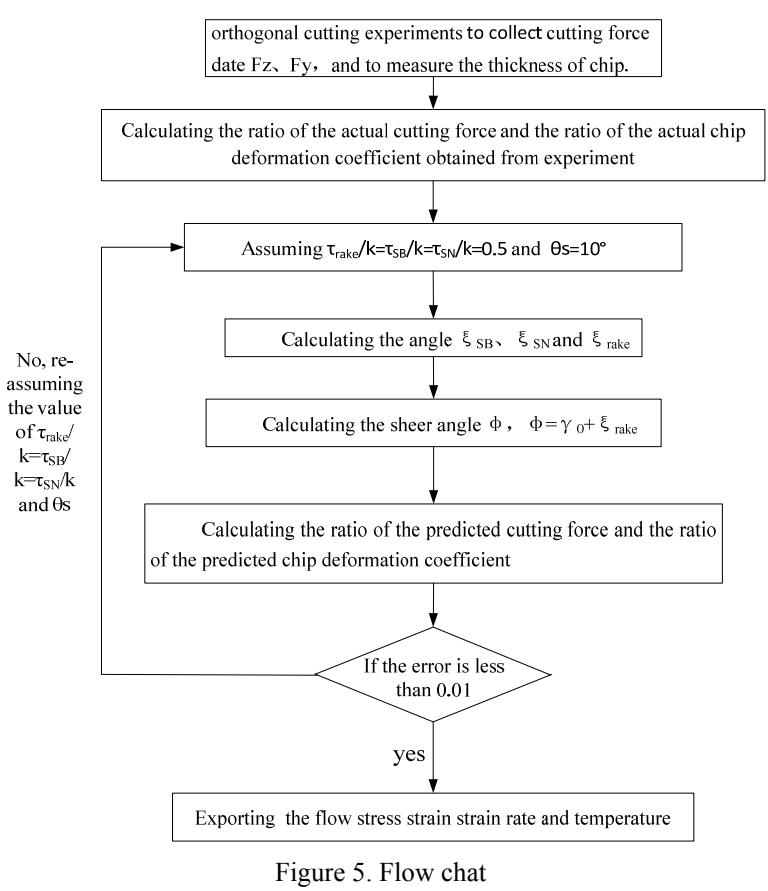

2) Non-linear fitting of thermodynamics constitutive equation

The thermodynamic constitutive equations were non-linearly fitted with the least-squares method according to the four parameters (flow stress, strain ,strain rate and temperature), and the material coefficients were simultaneously determined which make the norm of the residual sum of squares between the calculated modified flow stress value and the actual value obtained by experiments be less 0.01 . The fitting parameters of high-temperature alloy Incoloy 907 were as follows in Tab.4

TABLE4. MATERIAL COEFFICIENTS OF INCOLOY 907

\begin{tabular}{|l|l|l|l|l|l|l|}
\hline B1 & B2 & B & A & n & m & Ya \\
\hline 0.1012 & -0.1212 & 1.0903 & -0.9011 & 3.5514 & 0.0875 & 977.0904 \\
\hline
\end{tabular}

The ultimate thermodynamical constitutive equations for workpiece material Incoloy 907 was obtained as:

$$
\sigma=\left(1.0903 \varepsilon_{p}^{3.5514}\right)\left(1+0.1012 T\left[\dot{\varepsilon}_{P}\right]^{\frac{1}{0.0875}}+0.1212 T e^{-0.9011\left(1-\frac{T}{T_{t}}\right)}\right)+977.0904
$$

From the research of Hayakawa $\mathrm{K}^{[20]}$, the strain and stress at normal temperature of tool material WC-Co were as follows in Tab.5.

TABLE5. MATERIAL STRAIN AND STRESS DATA OF TOOL MATERIAL WC-CO

\begin{tabular}{|l|l|l|l|l|l|}
\hline strain & 0 & 0.005 & 0.01 & 0.015 & 0.02 \\
\hline stress $(\mathrm{MPa})$ & 0 & 2000 & 2700 & 2800 & 3000 \\
\hline
\end{tabular}

The ultimate thermodynamical constitutive equations for tool material $\mathrm{WC}-\mathrm{CO}$ was obtained as:

$$
\sigma=\left(2.029 \varepsilon^{0.2735}\right)\left(1+0.0001 T\left[\dot{\varepsilon}_{P}\right]^{\frac{1}{0.0001}}-0.6906 T e^{0.3047\left(1-\frac{T}{1372}\right)}\right)+2.1
$$

To validate the orthogonal cutting model, the predicted and experimentally measured cutting temperature and Cutting force were compared and their differences were discussed. 


\section{Experimental verification}

Orthogonal cutting tests were performed on a numerically controlled lathe equipped with a specially designed experimental set-up. In measuring the cutting force components (tangential force and the thrust force) a Kistler-type SDC CSM19 three-component piezoelectric dynamometer was used. The tangential force component was measured in the direction of the primary motion and the thrust force component in the direction of feed motion. The experimental value were shown in Tab.6.

\section{Simulation results and discussion}

\section{1) Flow stress and equivalent strain}

The predicted flow stress of workpiece and chip when two-dimensional orthogonal cutting INCOLOY when cutting speed was $100 \mathrm{~m} / \mathrm{min}$ were shown in Fig.6.It can be seen from Fig.7 that the flow stress of workpiece and chip decreased smoothly when the tool had just cut into the workpiece, then the flow stress of workpiece fluctuated within a certain range when steady-state cutting whose reasons were as follows: firstly, the increasing temperature of the shear zone would cause the thermal softening of workpiece material which would make the material flow stress reduction, simultaneously ,the decreased flow stress would make the heat reduction which would make the uncut material hardened and would cause the flow stress increased. It can also be seen from Fig.7 that the flow stress in the chip was gradually released with the running-out of the chip from the rake face of the tool, and the flow stress in the workpiece only existed near the cutting region while away from the cutting region the regional stress was small.

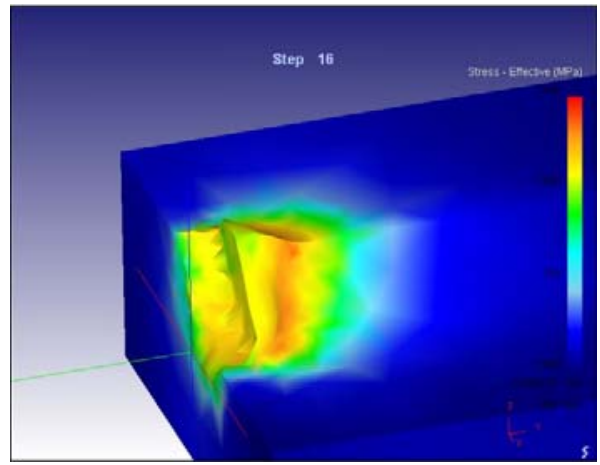

(a) The initial cutting stress field

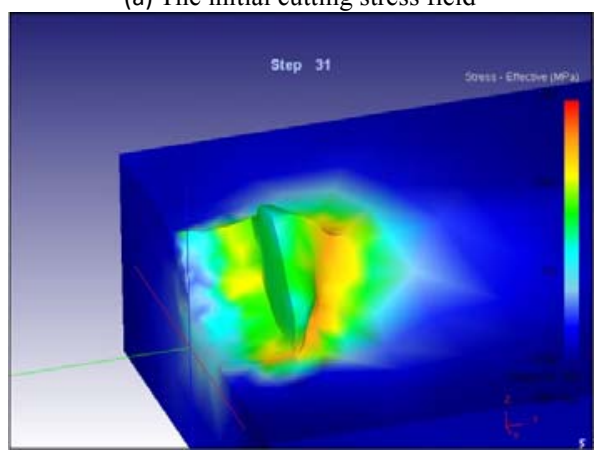

(b) The cutting stress field of 31 steps

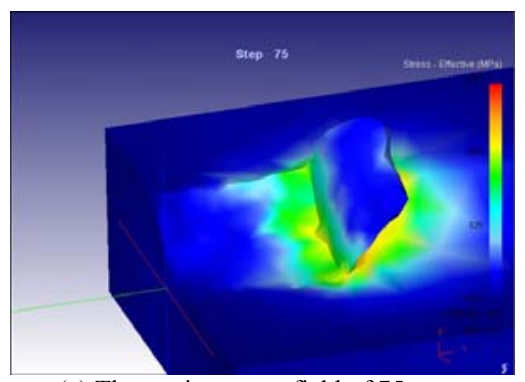

(c) The cutting stress field of 75 steps

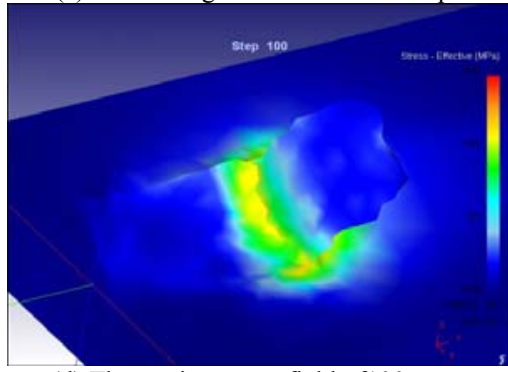

(d) The cutting stress field of100 steps

Figure6. Distribution of equivalent stress

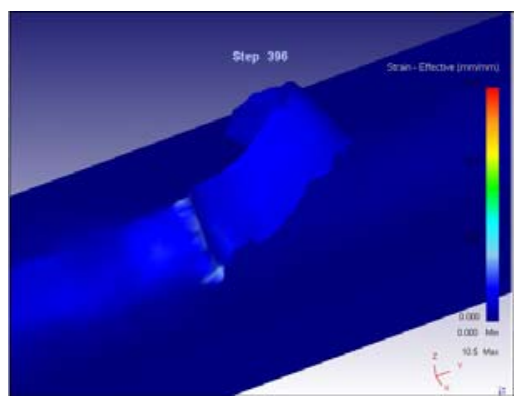

(a)Non-uniform strain

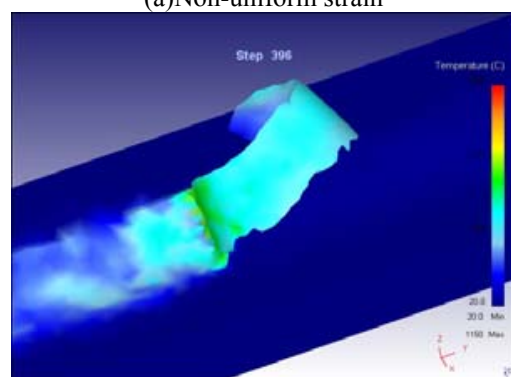

(b) The corresponding cutting temperature field for the non-uniform Strain

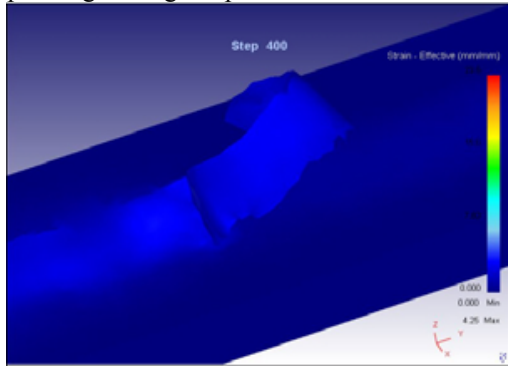

(c)Uniform strain 


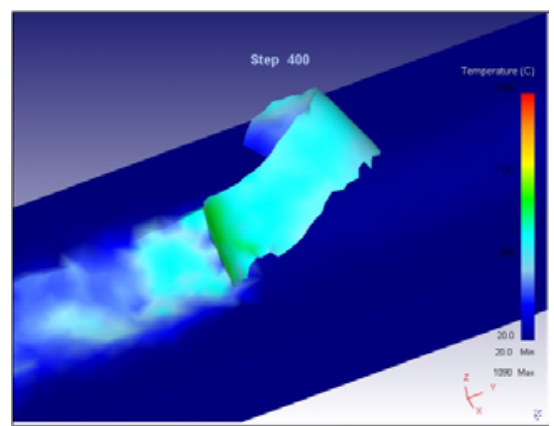

(d) The corresponding cutting temperature field for the uniform strain

Figure7. Distribution of equivalent strain

The predicted equivalent strain of workpiece and chip when two-dimensional orthogonal cutting Incoloy 907 when cutting speed was $100 \mathrm{~m} / \mathrm{min}$ were shown in Fig.7(a)and(c).The corresponding cutting temperature field were shown in Fig.7(b)and(d). It can be seen from Fig.8 that the maximum equivalent strain distributed in the area where the chip was about to leave the rake face of the tool. When steady-state cutting, the strain of workpiece was uniform, as the cutting process progressed the strain became uneven, and the fluctuations of strain were taken place in the workpiece whose fluctuations in frequency was lower than the fluctuations of stress. The reasons were as follows: the dynamic recrystallization of the materials would cause the stress softening of the material as the increasing of the cutting temperature, simultaneously, changes in microstructure took place with the deformation. The small differences of microstructure in the spatial distribution could cause a large difference of macroscopic stress and strain for the non-linear relationship between the microstructure changes and the macro-deformation, samely, the macro-inhomogeneity of deformation could also cause more uniform microstructure which would make the strain fluctuation.

\section{2) Cutting temperature}

The predicted temperature at different cutting speed were showed in Fig.8. It can be obviously seen that the predicted temperature increased with the increasing of the cutting speed. The predicted temperature reached to $1290{ }^{\circ} \mathrm{C}$ when the cutting speed was $300 \mathrm{~m} / \mathrm{min}$ while the cutting speed was $100 \mathrm{~m} / \mathrm{min}$, the predicted temperature only reached to $810{ }^{\circ} \mathrm{C}$.

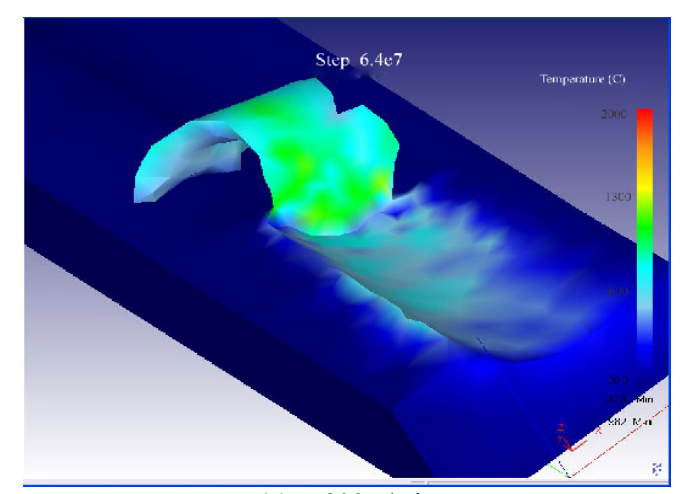

(a) $\mathrm{v}=300 \mathrm{~m} / \mathrm{min}$

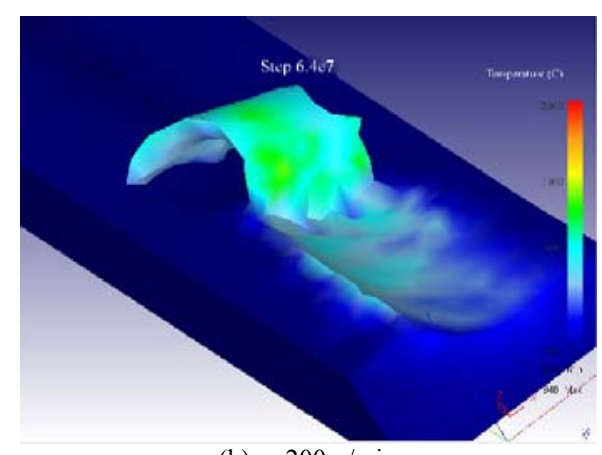

(b) $\mathrm{v}=200 \mathrm{~m} / \mathrm{min}$

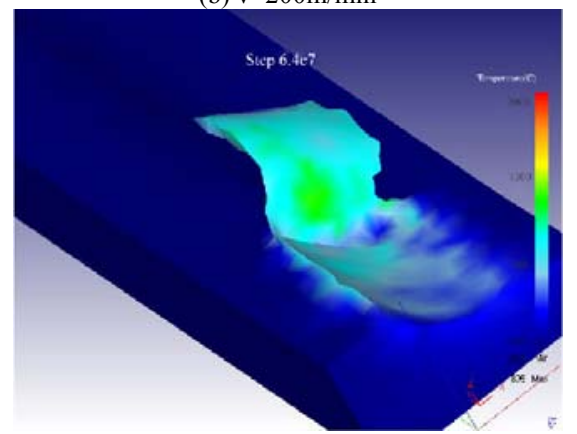

(c) $\mathrm{v}=150 \mathrm{~m} / \mathrm{min}$

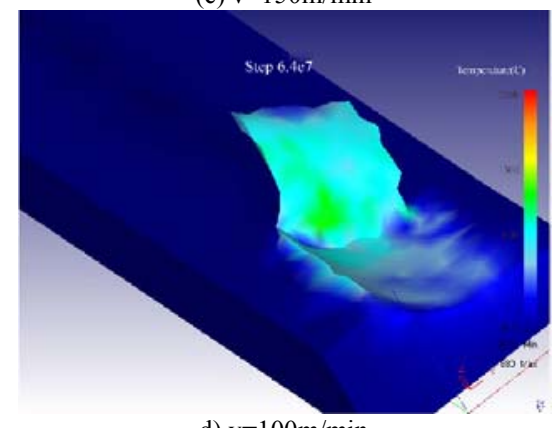

d) $\mathrm{v}=100 \mathrm{~m} / \mathrm{min}$

Figure8. Predicted temperature

\section{3) Cutting force}

The predicted cutting force at different cutting speed were showed in Fig.9.

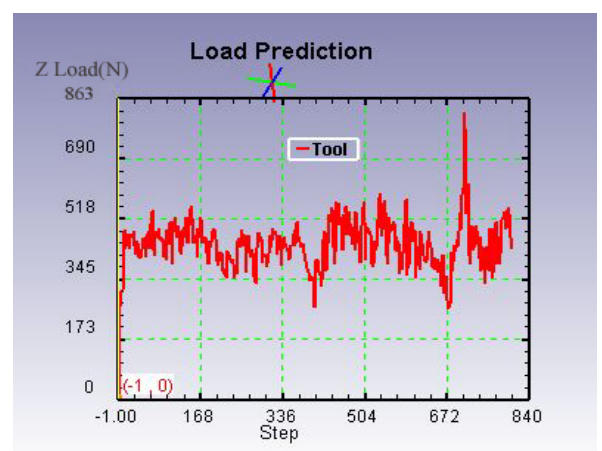

(a) $\mathrm{v}=200 \mathrm{~m} / \mathrm{min}$ 

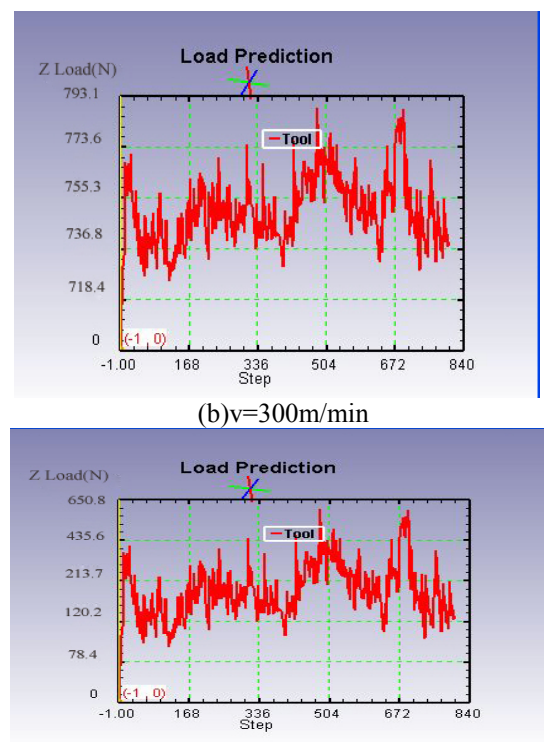

(c) $\mathrm{v}=150 \mathrm{~m} / \mathrm{min}$

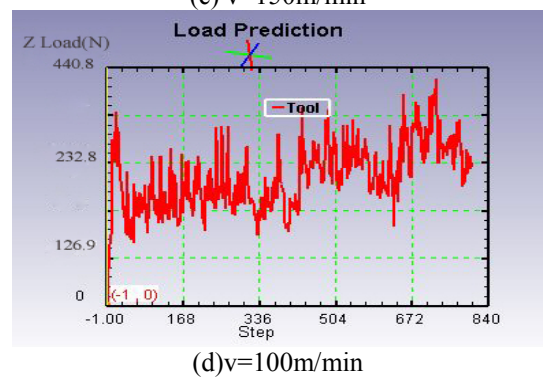

Figure9. Predicted cutting force

In order to verify the correctness of the obtained finite element model, the experimental value and predicted value were compared which were shown in Tab.6. The results showed that the relative error between the experimental value and predicted value was less than $10 \%$ which proved the correctness of the obtained model for the model was built under some certain assumption. This result permits to assess that the assumption of the T-C-Q model used in the present study appears to be reasonable.Tab.6 gives the experimental value and predicted value.

TABLE 6. THE EXPERIMENTAL VALUE AND PREDICTED VALUE (THE DISTANCE IS0.05MM BETWEEN TOOL RAKE FACE AND CHIP EDGE)

\begin{tabular}{|c|c|c|c|c|}
\hline Cutting speed $(\mathrm{m} / \mathrm{min})$ & 100 & 150 & 200 & 300 \\
\hline $\begin{array}{c}\text { Predicted cutting } \\
\text { force/ } \mathrm{N}\end{array}$ & 431.5 & 645.41 & 860.24 & 720 \\
\hline $\begin{array}{c}\text { Experimental cutting } \\
\text { force } / \mathrm{N}\end{array}$ & 422.23 & 597 & 789 & 661 \\
\hline Relative error & $2.2 \%$ & $8.3 \%$ & $9.5 \%$ & $8.8 \%$ \\
\hline $\begin{array}{c}\text { Predicted } \\
\text { temperatrue } /{ }^{\circ} \mathrm{C}\end{array}$ & 810 & 1010 & 1220 & 1290 \\
\hline $\begin{array}{c}\text { Experimental } \\
\text { temperatrue } /{ }^{\circ} \mathrm{C}\end{array}$ & 637 & 957 & 1128 & 1230 \\
\hline Relative error & $8.7 \%$ & $5.5 \%$ & $8.1 \%$ & 4.87 \\
\hline
\end{tabular}

\section{CONCLUSION}

A finite element analysis (FEA) of machining for Incoloy907 is presented. In particular, the thermodynamical constitutitve equation (T-C-E) in FEA is applied for both work piece material and tool material .Research results indicated that a reasonable prediction of temperature and cutting force are obtained when using model T-C-E in high speed machining. These evidences permit to establish that good numerical results can be obtained when simulating cutting conditions similar to those characterize material constitutive law. Therefore, it can be concluded that the T-C-E model in this paper can be employed to study the orthogonal process of Incoloy907 and to predict the reality of the temperature and cutting force with satisfactory accuracy.

\section{ACKNOWLEDGMENTS}

The author gratefully acknowledges Prof. Huanjie Zhang at the Binzhou Bohai Piston Limited Company for providing the experimental results for this research,and also acknowledges the Binzhou Polytechnic Natural Science Foundation(2010xykt03).

\section{CONFERENCES}

[1] E. O. Ezugwu. Journal of Materials Processing Technology.185 (2007):60-71.

[2] F.C. Campbell. Manufacturing Technology for Aerospace Structural Materials. (2006) :211-272.

[3] RL Kennedy, RM Forbes Jones, RM Davis,MG Benz and, WT Carter. Vacuum47(1996): 819-824.

[4] J.S. Wan, Z.F. Yue. Materials Science and Engineering: A.392(2005): 145-149

[5] J. W. Brooks. Materials \& Design.21(2000): 297-303.

[6] T. Kitashima, H. Harada. Acta Materialia.57(2009): 2020-2028.

[7] T. Link, S. Zabler, A. Epishin, A. Haibel, M. Bansal, X. Thibault r. Materials Science and Engineering: A.425(2006): 47-54

[8] Florian Pyczak, Steffen Neumeier, Mathias Göken. Materials Science and Engineering: A.510-511(2009): 295-300.

[9] E. O. Ezugwu, Z. M. Wang. Journal of Materials Processing Technology.68(1997):262-274.

[10] Domenico Umbrello. Journal of materials processing technology. 196(2008):79-87.

[11] Songwon Seoa, Oakkey Minb, Hyunmo Yang. International Journal of Impact Engineering 31(2005):735-754.

[12] D.Rittel , Z.G. Wang. Mechanics of Materials. 40(2008):629-635.

[13] Woei-Shyan Lee, Chi-Feng Lin. Journal of Materials Processing Technology .75(1998):127-136.

[14] Y.Q. Wang, G. Sayre. Surface and Coatings Technology.203(2008): 256-263.

[15] A.K. Koul, F.B. Pickering. Scripta Metallurgica.16(1982): 119-124

[16] S. Miller. Interdisciplinary Science Review.21(1996): 117-129.

[17] China Aeronautical Materials Handbook prepared by the Commission. China Aeronautical Materials Handbook (Volume 2) High-temperature deformation alloy High-temperature casting alloy[M].Beijing: Standards Press of China.

[18] D. Umbrelloa, R. M Saoubib, J.C.Outeiro . International Journal of Machine Tools \& Manufacture .47(2007):462-470.

[19] George Z. Voyiadjis , Amin H. Almasri. Mechanics of Materials 40(2008):549-563.

[20] M.Jr.Vaz. Journal of Brazilian Society of Mechanical Science. 22(2000):179-188 